\title{
Design, Synthesis, and Anticancer Activities of Novel 2-Amino-4-phenylthiazole Scaffold Containing Amide Moieties
}

\author{
Zhi-Hua Zhang, ${ }^{1}$ Hong-Mei Wu, ${ }^{1}$ Sai-Nan Deng, ${ }^{2}$ Xiao-Yu Cai, ${ }^{2}$ Yu Yao, ${ }^{2}$ \\ Muriira Cyrus Mwenda, ${ }^{2}$ Jin-Yin Wang, ${ }^{2}$ Dong Cai $\mathbb{D}^{3},{ }^{3}$ and Yu Chen $\mathbb{D}^{4}$, \\ ${ }^{1}$ School of Chemical and Environmental Engineering, Liaoning University of Technology, Jinzhou 121001, China \\ ${ }^{2}$ College of Pharmacy, Jinzhou Medical University, Jinzhou 121001, China \\ ${ }^{3}$ College of Public Basic Sciences, Jinzhou Medical University, Jinzhou 121001, China \\ ${ }^{4}$ School of Life Science and Biopharmaceutics, Shenyang Pharmaceutical University, Shenyang 110016, China
}

Correspondence should be addressed to Dong Cai; caidong0804@163.com and Yu Chen; gzweishengwu@126.com

Received 25 July 2018; Revised 4 September 2018; Accepted 26 September 2018; Published 18 October 2018

Academic Editor: Zhen Cheng

Copyright (c) 2018 Zhi-Hua Zhang et al. This is an open access article distributed under the Creative Commons Attribution License, which permits unrestricted use, distribution, and reproduction in any medium, provided the original work is properly cited.

\begin{abstract}
Appropriately substituted 2-amino-4-phenylthiazole derivatives were designed and synthesized according to the structural characteristics of crizotinib. The obtained compounds were characterized using ${ }^{1} \mathrm{H}$ NMR, ${ }^{13} \mathrm{C}$ NMR, and HRMS. The target compounds 5a-o were evaluated for their in vitro antiproliferative activity against A549, HeLa, HT29, and Karpas299 human cancer cell lines. Based on results of biological studies, some of these compounds exhibited significant antiproliferative activity. Compound $\mathbf{5 b}$ possessed outstanding growth inhibitory effects on the four cell lines, especially for HT29 cell with $\mathrm{IC}_{50}$ value of $2.01 \mu \mathrm{M}$. Along with the biological assay data, a molecular docking study suggests that the target compounds were a potential inhibitor.
\end{abstract}

\section{Introduction}

The 2-aminothiazole scaffold has played an important role in medicinal chemistry and drug discovery research. The derivatives of 2-aminothiazole are recognized by a wide range of pharmacological activities, including anticancer [1-3], anticonvulsant $[4,5]$, antidiabetic $[6,7]$, antihypertensive [8], anti-inflammatory $[9,10]$, antiviral [11], antimicrobial $[12,13]$, and antileishmanial [14] activities and neuroprotective agents [8]. Numerous drugs and active compounds (Figure 1) containing 2-aminothiazole or 2-amino4-phenylthiazole scaffold have been exhibiting a wide range of strong antitumor activities. Compound 1 showed low nanomolar in vitro antitumor activity and selectivity toward cancer cells over normal phenotype cells, which were identified as Hec1/Nek2 inhibitor [3]. Compound 2 (CYC116, Cyclacel) was an effective Aurora A/B inhibitor and a slightly weaker inhibitor of VEGFR2 and was currently in Phase I clinical trials $[15,16]$. Compound 3 (dasatinib, BMS354825) was a novel, highly potent, and multitargeted inhibitor of Abl, Src, and c-Kit kinase, which was more potent than imatinib against unmutated BCR-ABL [17].

Developed by Pfizer Co., crizotinib was a potent and selective small-molecule dual inhibitor of the mesenchymalepithelial transition factor (c-Met) kinase and anaplastic lymphoma kinase (ALK), possessing effective tumor growth inhibition and good pharmaceutical properties. In general, the cocrystal structure of crizotinib deposited in c-Met (PDB code 2WGJ, Figure 2(a)) revealed that a hydrophobic 2,6dichloro-3-fluorobenzyl moiety formed $\pi-\pi$ stacking interaction with Tyr1230 of c-Met kinase. In addition, this aryl fragment was extended into the U-shaped binding site, which adopted an ideal conformation for involvement in a hydrophobic effect with Met1211 and Gly1163. Furthermore, the 2-aminopyridine moiety formed two hydrogenbonding interactions with the Met1160 and Pro1158 of the hinge region [18-20]. The 4-(1H-pyrazol-1-yl)piperidine moiety faced to the solvent accessible region, indicating that this hydrophobic fragment was relatively prone to bioisosteric replacement [19]. 

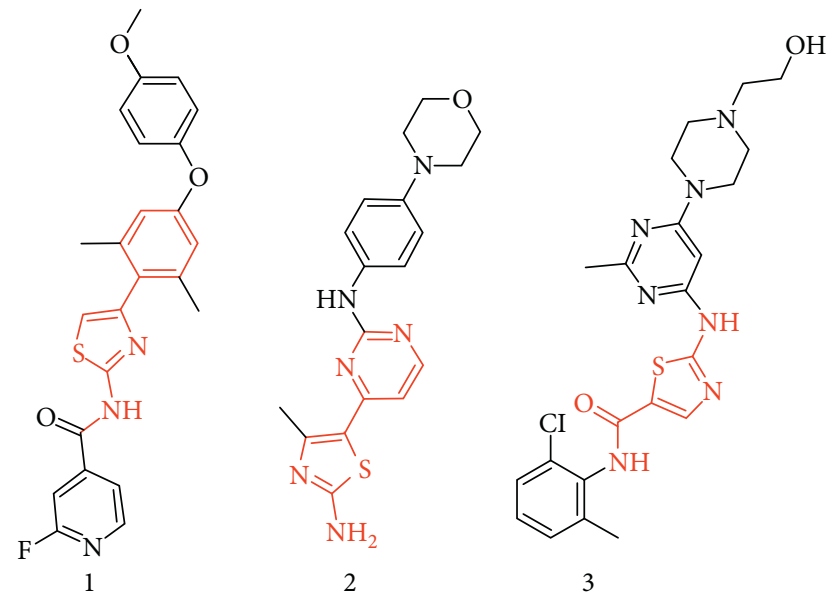

FIGURE 1: Structures of bioactive 2-aminothiazole derivatives.

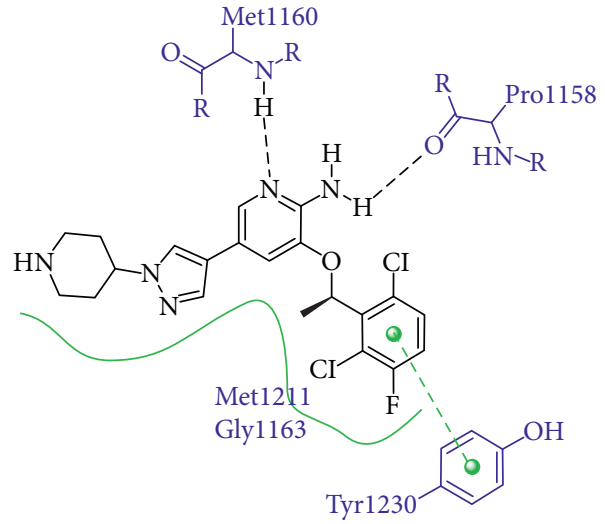

(a)

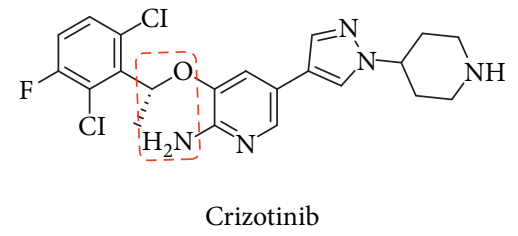

c-Met/ALK inhibitor, $\mathrm{IC}_{50}=11 \mathrm{nM} / 24 \mathrm{nM}$,

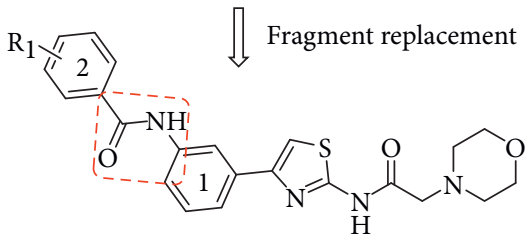

Compounds 5a-o

(b)

Figure 2: (a) Cocrystal structure of crizotinib bound to c-Met (2WGJ). Black dashed line indicates hydrogen bonds. Green solid line shows hydrophobic interactions, and green dashed line shows $\pi-\pi$ interactions. (b) Design of novel target compounds based on crizotinib.

To design a novel scaffold of c-Met inhibitor (Figure 2(b)), a bioactive 2-amino-4-phenylthiazole scaffold was used as the skeleton. In the meanwhile, 2-aminopyridine moiety in crizotinib was replaced by the amide moiety, and the ability to efficiently form hydrogen bonds was retained. As the cocrystal structure of crizotinib has demonstrated that the halogen substitution at the phenyl ring is most favorable, we decided to modify group $R_{1}$ of the terminal phenyl ring 2 so as to investigate whether the cellular activity can be improved. Moreover, a flexible 2-morpholinoacetamido motif was introduced instead of the piperidinyl moiety in crizotinib. According to Figure 2(a), the possible additional hydrogen bond may be established in this way. In the proposed study, a novel 2-amino-4-phenylthiazole scaffold containing amide moieties was synthesized and evaluated for its antiproliferative activities.

\section{Results and Discussion}

2.1. General Synthesis of the Target Compounds. The synthetic route of the target compounds in the current work is depicted in Scheme 1. 2-Bromo-1-(3-nitrophenyl)ethanone was warmed with thiourea in ethanol to obtain compound $\mathbf{1}$ in a good yield. The amino moiety of compound $\mathbf{1}$ was $N$ acylated with the excess chloroacetyl chloride in dichloromethane at room temperature to yield compound 2 . In search of effective methods to prepare compound 2 by reacting compound $\mathbf{1}$ with 2-chloroacetic anhydride, we have found that 2 -aminothiazole derivatives are quite inactive against a nucleophilic reaction. With abovementioned compounds, the reaction is not complete under reflux for 24 h. Compound 2 reacted with morpholine using $\mathrm{Na}_{2} \mathrm{CO}_{3}$ as base in refluxing anhydrous ethanol to afford compound 3. Compound $\mathbf{4}$ was prepared by treatment of compound $\mathbf{3}$ with reducing reagent tin (II) chloride dihydrate in refluxing ethanol. Eventually, intermediate 4 reacted with a series of acyl chloride to give the target compounds $5 \mathbf{a}-\mathbf{o}$ based on the published procedure [21].

Reagents and conditions: (a) thiourea, ethanol, and reflux; (b) chloroacetyl chloride, $\mathrm{CH}_{2} \mathrm{Cl}_{2}, \mathrm{Et}_{3} \mathrm{~N}$, r.t.; (c) morpholine, ethanol, $\mathrm{K}_{2} \mathrm{CO}_{3}$, r.t.; (d) $\mathrm{SnCl}_{2} \cdot 2 \mathrm{H}_{2} \mathrm{O}$, ethanol, reflux; (e) substituted acyl chloride, $\mathrm{CH}_{2} \mathrm{Cl}_{2}$, $\mathrm{Et}_{3} \mathrm{~N}$, r.t.; 

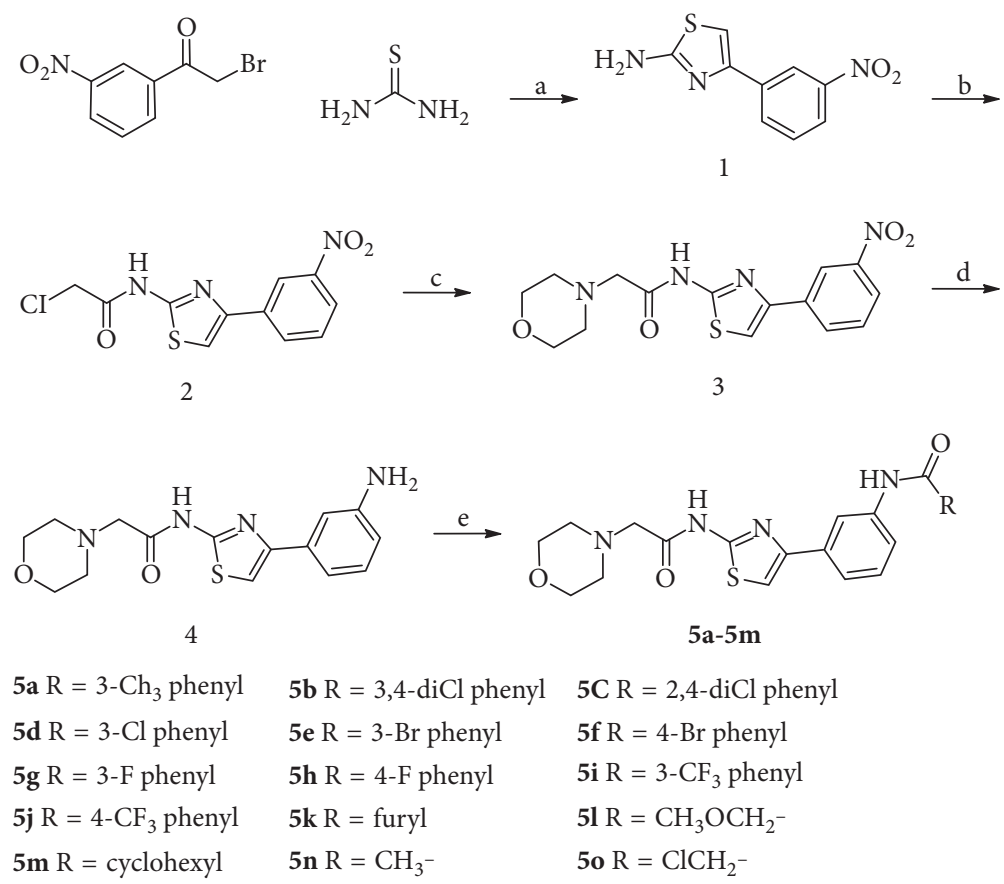

Scheme 1: General synthesis of the target compounds.

2.2. In Vitro Antiproliferative Activity. The obtained compounds were evaluated for antiproliferative activities with the application of the MTT method using human nonsmall cell lung cancer cell (A549), human cervical cancer cell (HeLa), human colon cancer cell (HT29), and human lymphoma cell line (Karpas299). Crizotinib was employed as positive control. The results are shown in Table 1. Some of these compounds displayed better growth inhibitory effects especially for HT29 cell.

In the structure of compounds $5 \mathbf{a}, \mathbf{5 d}, \mathbf{5 e}, \mathbf{5 g}$, and $\mathbf{5 j}$, the metasubstitution on the benzene ring 2 (Figure 2(b)) was modified to determine the contribution of this substitution to the antiproliferative activity. In vitro activity of these compounds demonstrated that the meta-halogen- (especially chloro-) substituted benzene ring $\mathbf{2}$ was favorable for anticancer activity. Compounds $\mathbf{5 b}$ and $\mathbf{5 d}$ compared with $5 \mathrm{c}$ have shown that 3,4-diCl- or 3-Cl-substituted benzene ring 2 (Figure 2(b)) are better than 2,4-diCl substitution on the corresponding benzene ring in terms of inhibitory activity. This result suggested that the ortho substituent on benzene ring 2 are not conducive to antiproliferative activity. Compound 5k, with a furan ring at $\mathrm{R}$ (Scheme 1) instead of the benzene ring 2 , was only low activity toward four tumor cells, suggesting that the substituted phenyl groups were more beneficial than a furan ring to the inhibitory activity. Compound 51-o displayed no inhibitory activity toward test cell lines probably due to the lack of the side chains containing aromatic amide groups.

2.3. In Vitro Enzymatic Assays. Finally, the inhibitory effect of compound $\mathbf{5 b}$ against c-Met kinase was further examined. According to Table 2, compound $\mathbf{5 b}$ exhibited a moderate c-Met enzymatic potency, suggesting that the inhibition of
TABLE 1: $\mathrm{IC}_{50}(\mu \mathrm{M})$ values of the target compounds.

\begin{tabular}{lcccc}
\hline \multirow{2}{*}{ Compound } & \multicolumn{4}{c}{$\mathrm{IC}_{50}(\mu \mathrm{M})$} \\
& $\mathrm{A} 549$ & $\mathrm{HeLa}$ & $\mathrm{HT} 29$ & Karpas299 \\
\hline $\mathbf{5 a}$ & $>40$ & $>40$ & $>40$ & $>40$ \\
$\mathbf{5 b}$ & 21.33 & 9.56. & 2.01 & 4.46 \\
$\mathbf{5 c}$ & $>40$ & 30.77 & 18.65 & $>40$ \\
$\mathbf{5 d}$ & 17.32 & 10.86 & 2.19 & 11.12 \\
$\mathbf{5 e}$ & $>40$ & 15.01 & 12.52 & 19.37 \\
$\mathbf{5 f}$ & $>40$ & 26.11 & 15.48 & 23.03 \\
$\mathbf{5 g}$ & 30.56 & 18.14 & 5.22 & 25.93 \\
$\mathbf{5 h}$ & $>40$ & 25.98 & 18.73 & $>40$ \\
$\mathbf{5 i}$ & $>40$ & 24.72 & 8.25 & 10.86 \\
$\mathbf{5 j}$ & $>40$ & $>40$ & 15.74 & 25.28 \\
$\mathbf{5 k}$ & $>40$ & 35.81 & 21.16 & $>40$ \\
$\mathbf{5 l}$ & $>40$ & $>40$ & $>40$ & $>40$ \\
$\mathbf{5 m}$ & $>40$ & $>40$ & $>40$ & $>40$ \\
$\mathbf{5 n}$ & $>40$ & $>40$ & $>40$ & $>40$ \\
$\mathbf{5 0}$ & $>40$ & $>40$ & $>40$ & $>40$ \\
Crizotinib & 2.26 & 1.09 & 1.10 & 0.02 \\
\hline
\end{tabular}

TABle 2: Enzymatic activity of the compound $\mathbf{5 b}$ against c-Met kinase.

\begin{tabular}{lc}
\hline Compound & c-Met $\left(\mathrm{IC}_{50}, \mathrm{nM}\right)$ \\
\hline $\mathbf{5 b}$ & 180.63 \\
Crizotinib & 11.51 \\
\hline
\end{tabular}

c-Met kinase may be a main mechanism for the antiproliferative activity of the selected compound $\mathbf{5 b}$.

2.4. Western Blot Analysis. The results from cell proliferation activities showed that some target compounds, especially for $\mathbf{5 b}$, strongly inhibited the growth of HT29 cells better than 
that of the Karpas299 cells (ALK overexpression). To further elucidate the molecular mechanisms of target compounds, compounds $\mathbf{5 b}$ and $\mathbf{5 e}$ were selected for further studies. HT29 cell was treated with HGF, and the activation of c-Met was subsequently monitored by western blot analysis. As shown in Figure 3, crizotinib $(5 \mu \mathrm{M})$ obviously inhibited the HGF-induced c-Met phosphorylation in HT29 cells. When HT29 cell was treated with $5 \mu \mathrm{M}$ of compounds $\mathbf{5 b}$ and $\mathbf{5 e}$ for $24 \mathrm{~h}$, it could be observed that the compound $\mathbf{5 b}$ obviously blocked the MET signaling pathway. Compound 5e with a relatively low activity has not marked inhibition of the c-Met phosphorylation. These data suggested that the target compounds, especially for compound $\mathbf{5 b}$, might be adopted as a novel c-Met inhibitor.

2.5. Molecular Properties and Drug-likeness. Molecular properties and drug-likeness model score (a combined effect of physicochemical properties, pharmacokinetics, and pharmacodynamics of a compound and is represented by a numerical value) were calculated online by MolSoft software (http://molsoft.com/mprop). Estimation of druglikeness properties are presented in Table 3.

For most target compounds, the parameters such as molecular weight (MW), number of hydrogen bond acceptors (HBA), number of hydrogen bond donors (HBD) and MolLogP were all in the range of Lipinski's "rule of five" [22]. The molecular weight of compound $\mathbf{5 e}$ and $\mathbf{5 f}$ was slightly beyond the range of acceptable limit. Therefore, it was possible that these target compounds might have acceptable physicochemical properties of oral candidate drugs.

Additionally, the number of potential hydrogen bond donors and acceptors in the ligand must be appropriate. The difference existing in HBA between the target compounds and crizotinib is presented in Table 3 . An excessive number of hydrogen bond acceptors in the target compounds may lead to redundant affinities and intramolecular hydrogen bonds. Besides, these analyses were consistent with the observation that the biological activity of the target compounds was worse than crizotinib.

2.5. Molecular Docking. To elucidate the active compound to c-Met, we determined the c-Met kinase-binding domain (PDB code 2WGJ) in complex with the representative compound $\mathbf{5 b}$. Figure 4 showed the superimposition of crizotinib and the docked compound $\mathbf{5 b}$. The two compounds were embedded in the "U shape" pocket of c-Met. The thiazole ring of compound $\mathbf{5 b}$ formed a $\pi-\pi$ interaction with Tyr 1230 of c-Met protein. The similar interaction between crizotinib and Tyr 1230 has been described in Figure 2(a). Additionally, the compound $\mathbf{5 b}$ also formed two hydrogen bonds in the active site with Asp1164 and Met1160, respectively. However, the phenyl ring 2 (Figure 2(b)) of compound $\mathbf{5 b}$ faced the solvent accessible region, similar to the hydrophobic 4-(1H-pyrazol-1-yl)piperidine moiety of crizotinib, which may explain the cause of slightly worse antiproliferative activity of the target compounds.

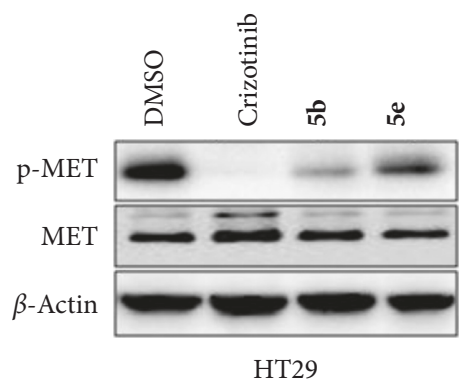

FIgUre 3: Effect of Crizotinib and the target compounds on MET activity in HT29 cancer cell.

TABle 3: Molecular properties and drug-likeness.

\begin{tabular}{lcccccc}
\hline Compound & MW & HBA & HBD & MolLogP & MolPSA & Score \\
\hline $\mathbf{5 a}$ & 436.16 & 6 & 2 & 3.36 & 67.89 & 0.66 \\
$\mathbf{5 b}$ & 490.06 & 6 & 2 & 4.27 & 67.89 & 1.07 \\
$\mathbf{5 c}$ & 490.06 & 6 & 2 & 4.27 & 67.89 & 1.16 \\
$\mathbf{5 d}$ & 456.10 & 6 & 2 & 3.67 & 67.89 & 0.78 \\
$\mathbf{5 e}$ & 500.05 & 6 & 2 & 3.81 & 67.89 & 0.57 \\
$\mathbf{5 f}$ & 500.05 & 6 & 2 & 3.81 & 67.89 & 0.96 \\
$\mathbf{5 g}$ & 440.13 & 6 & 2 & 3.23 & 67.89 & 1.12 \\
$\mathbf{5 h}$ & 440.13 & 6 & 2 & 3.23 & 67.89 & 0.71 \\
$\mathbf{5 i}$ & 490.13 & 6 & 2 & 4.20 & 67.89 & 0.61 \\
$\mathbf{5 j}$ & 490.13 & 6 & 2 & 4.20 & 67.89 & 0.66 \\
$\mathbf{5 k}$ & 412.12 & 7 & 2 & 2.19 & 76.47 & 0.73 \\
$\mathbf{5 l}$ & 390.14 & 7 & 2 & 1.12 & 76.38 & 0.70 \\
$\mathbf{5 m}$ & 428.19 & 6 & 2 & 3.16 & 68.09 & 0.77 \\
$\mathbf{5 n}$ & 360.13 & 6 & 2 & 1.52 & 68.07 & 0.60 \\
$\mathbf{5 0}$ & 394.09 & 6 & 2 & 1.74 & 67.95 & 0.50 \\
Crizotinib & 449.12 & 4 & 3 & 3.95 & 62.56 & 0.36 \\
\hline
\end{tabular}

MW: molecular weight (acceptable range $\leq 500$ ); HBA: number of hydrogen bond acceptors (acceptable range $\leq 10$ ); HBD: number of hydrogen bond donors (acceptable range $\leq 5$ ); MolLogP: $\log P$ value predicted by MolSoft (acceptable range $\leq 5$ ); MolPSA: topological polar surface area, (acceptable range $\leq 140 \AA^{2}$ ); score: drug-likeness model score. Compounds having zero or negative value should not be considered as drug-like candidate.

\section{Materials and Methods}

3.1. Chemicals, Reagents, and Instruments. Melting points were obtained in open capillaries using a WRS-1B melting point apparatus and were uncorrected. The ${ }^{1} \mathrm{H}$ and ${ }^{13} \mathrm{C}$ NMR spectra were recorded on a 400/54 Premium Shielded NMR Magnet System. Mass spectral data were collected from an Agilent 6200 Series TOF and 6500 Series Q-TOF LC/MS System B.05.01. (B5125) in positive ion modes.

4-(3-nitrophenyl)thiazol-2-amine 1: The mixture of 2bromo-1-(3-nitrophenyl)ethanone $(24.41 \mathrm{~g}, 0.10 \mathrm{~mol})$ and thiourea $(8.37 \mathrm{~g}, 0.11 \mathrm{~mol})$ in anhydrous ethanol $(200 \mathrm{~mL})$ was heated under reflux. After reaction was complete, the solvent was removed under vacuum, and saturated $\mathrm{NaHCO}_{3}$ was added to make the mixture basic $(\mathrm{pH}=8-9)$. The precipitate was collected by filtration, washed with water, and dried to yield the product.

Yellow solid; yield, $96.6 \%$; m.p.: $269.2^{\circ} \mathrm{C}-270.8^{\circ} \mathrm{C}$; HRMS $\left(\mathrm{m} / z\right.$ ): calcd. for $\mathrm{C}_{9} \mathrm{H}_{8} \mathrm{~N}_{3} \mathrm{O}_{2} \mathrm{~S}$ (neutral $\mathrm{M}+\mathrm{H}$ ) 222.03372, found 222.03385 . 


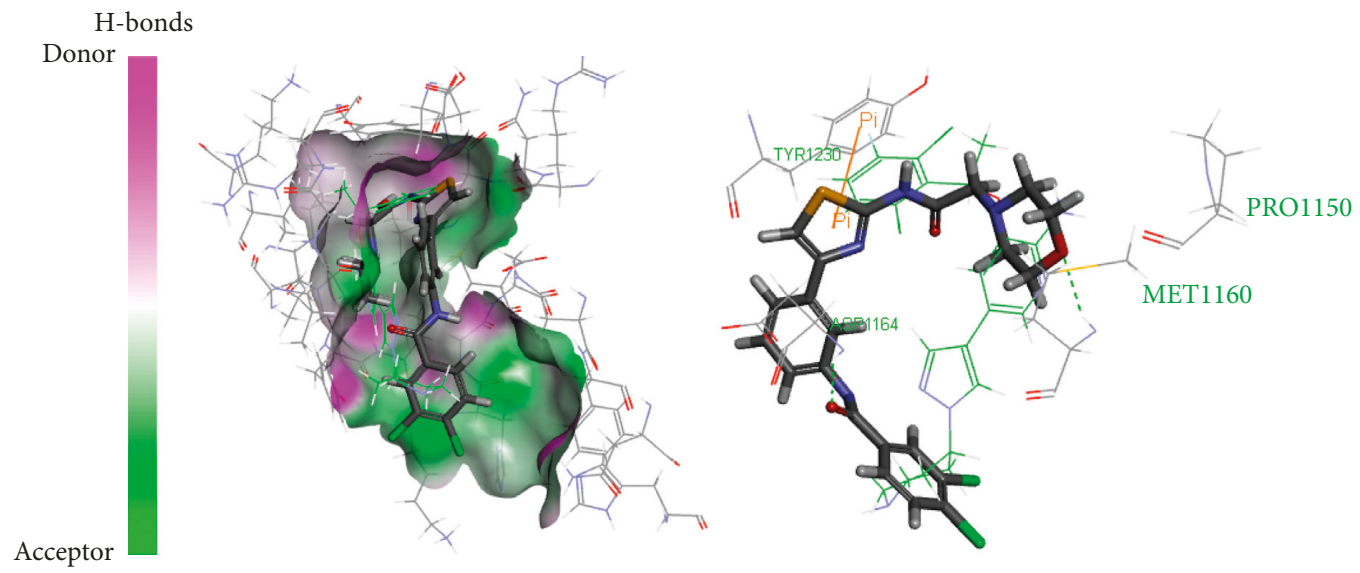

FIGURE 4: Binding mode of crizotinib (line) and compound $\mathbf{5 b}$ (stick).

2-chloro-N-(4-(3-nitrophenyl)thiazol-2-yl)acetamide 2 : To a solution of compound $\mathbf{1}(2.22 \mathrm{~g}, 0.01 \mathrm{~mol})$ and triethylamine $(1.52 \mathrm{~g}, 0.015 \mathrm{~mol})$ in anhydrous $\mathrm{CH}_{2} \mathrm{Cl}_{2}(40 \mathrm{~mL})$, chloroacetyl chloride $(1.35 \mathrm{~g}, 0.012 \mathrm{~mol})$ in $\mathrm{CH}_{2} \mathrm{Cl}_{2}(20 \mathrm{~mL})$ was added dropwise at $0^{\circ} \mathrm{C}$. The reaction mixture was stirred at room temperature. When the reaction was finished, saturated $\mathrm{Na}_{2} \mathrm{CO}_{3}$ was added to the solution until the $\mathrm{pH}$ became weakly basic. The mixture was separated with a separatory funnel, and the organic layer was washed with cold water, dried, and evaporated under vacuum to yield the product.

Yellow solid; yield, 82.6\%; m.p.: $218.1^{\circ} \mathrm{C}-219.9^{\circ} \mathrm{C}$; HRMS $(m / z)$ : calcd. For $\mathrm{C}_{11} \mathrm{H}_{9} \mathrm{ClN}_{3} \mathrm{O}_{3} \mathrm{~S}$ (neutral $\mathrm{M}+\mathrm{H}$ ) 298.00531, found 298.00506 .

2-morpholino-N-(4-(3-nitrophenyl)thiazol-2-yl)acetamide 3: A mixture of compound $2(2.97 \mathrm{~g}, 0.01 \mathrm{~mol})$, morpholine $(0.96 \mathrm{~g}, 0.011 \mathrm{~mol})$, potassium iodide $(0.17 \mathrm{~g}, 0.001 \mathrm{~mol})$, and anhydrous potassium carbonate $(4.14 \mathrm{~g}, 0.03 \mathrm{~mol})$ in anhydrous ethanol $(50 \mathrm{~mL})$ was heated under reflux for $12 \mathrm{~h}$. The excess of ethanol was removed under vacuum and the residue extracted with $\mathrm{CH}_{2} \mathrm{Cl}_{2}$. The organic layer was washed with water and dried, and the solvent was evaporated under vacuum. The residue was crystallized from ethanol to give the product.

Yellow solid; yield, $89.6 \%$; m.p.: $189.7^{\circ} \mathrm{C}-191.2^{\circ} \mathrm{C}$; HRMS $(m / z)$ : calcd. For $\mathrm{C}_{15} \mathrm{H}_{17} \mathrm{~N}_{4} \mathrm{O}_{4} \mathrm{~S}$ (neutral $\left.\mathrm{M}+\mathrm{H}\right) 349.09705$, found 349.10016 .

N-(4-(3-aminophenyl)thiazol-2-yl)-2-morpholinoacetamide 4: Compound $3(0.35 \mathrm{~g}, 0.001 \mathrm{~mol})$ was dissolved in ethanol $(20 \mathrm{~mL})$, and tin (II) chloride dihydrate $(0.45 \mathrm{~g}, 0.002 \mathrm{~mol})$ was added. The mixture was refluxed for 4 hours, and ethanol was evaporated under vacuum. The residue was dissolved into $\mathrm{CH}_{2} \mathrm{Cl}_{2}(40 \mathrm{~mL})$, washed with dilute $\mathrm{NaOH}$ solution $(1 \mathrm{~mol} / \mathrm{L}, 3 \times 20 \mathrm{~mL})$ and water $(3 \times 20 \mathrm{~mL})$, and dried and evaporated to dryness to give the product.

Yellow solid; yield, $84.9 \%$; m.p.: $187.3^{\circ} \mathrm{C}-189.0^{\circ} \mathrm{C}$; HRMS $(m / z)$ : calcd. For $\mathrm{C}_{15} \mathrm{H}_{19} \mathrm{~N}_{4} \mathrm{O}_{2} \mathrm{~S}$ (neutral $\mathrm{M}+\mathrm{H}$ ) 319.12287, found 319.12310 .

General procedure for preparation of compounds 5: To a solution of compound 4 (50 $\mathrm{mg}, 0.123 \mathrm{mmol})$ and triethylamine $(25 \mathrm{mg}, 0.246 \mathrm{mmol})$ in $\mathrm{CH}_{2} \mathrm{Cl}_{2}(20 \mathrm{~mL})$, the substituted acyl chloride $(0.184 \mathrm{mmol})$ was added, and the mixture was stirred for $8 \mathrm{~h}$ at room temperature. Then, water $(10 \mathrm{~mL})$ was added and extracted with $\mathrm{CH}_{2} \mathrm{Cl}_{2}$. The combined organic layer was dried and evaporated under vacuum. The crude product was purified by column chromatography on silica gel to give a target compound.

3-methyl-N-(3-(2-(2-morpholinoacetamido)thiazol-4-yl) phenyl)benzamide 5a: White solid; yield, 76.2\%; m.p.: $195.5^{\circ} \mathrm{C}-196.2^{\circ} \mathrm{C} ;{ }^{1} \mathrm{H}$ NMR $\left(400 \mathrm{MHz}, \mathrm{DMSO}-d_{6}\right) \delta 12.07(\mathrm{~s}$, $1 \mathrm{H}), 10.27(\mathrm{~d}, J=3.4 \mathrm{~Hz}, 1 \mathrm{H}), 8.39(\mathrm{~s}, 1 \mathrm{H}), 7.79-7.72(\mathrm{~m}$, $2 \mathrm{H}), 7.61(\mathrm{q}, J=6.6,5.5 \mathrm{~Hz}, 2 \mathrm{H}), 7.54(\mathrm{~d}, J=3.5 \mathrm{~Hz}, 1 \mathrm{H})$, $7.41-7.35(\mathrm{~m}, 3 \mathrm{H}), 3.62-3.53(\mathrm{~m}, 4 \mathrm{H}), 3.28(\mathrm{~d}, J=3.5 \mathrm{~Hz}$, $2 \mathrm{H}), 2.50(\mathrm{~d}, J=4.9 \mathrm{~Hz}, 4 \mathrm{H}), 2.38(\mathrm{~d}, J=3.5 \mathrm{~Hz}, 3 \mathrm{H}) ;{ }^{13} \mathrm{C}$ NMR $\left(101 \mathrm{MHz}, \mathrm{DMSO}-d_{6}\right) \delta 168.98,166.07,157.87,149.24$, $140.00,138.14,135.28,135.06,132.63,129.38,128.76,128.55$, 125.27, 121.55, 120.34, 118.41, 108.72, 66.57, 60.80, 53.39, 21.43; HRMS $(m / z)$ : calcd. For $\mathrm{C}_{23} \mathrm{H}_{25} \mathrm{~N}_{4} \mathrm{O}_{3} \mathrm{~S}$ (neutral $\mathrm{M}+$ H) 437.16474 , found 437.16675 .

3,4-dichloro-N-(3-(2-(2-morpholinoacetamido)thiazol-4yl)phenyl)benzamide $5 \boldsymbol{b}$ : White solid; yield, $75.1 \%$; m.p.: $158.4^{\circ} \mathrm{C}-160.1{ }^{\circ} \mathrm{C} ;{ }^{1} \mathrm{H}$ NMR (400 MHz, DMSO- $\left.d_{6}\right) \delta 12.07$ (s, $1 \mathrm{H}), 10.46(\mathrm{~d}, J=3.5 \mathrm{~Hz}, 1 \mathrm{H}), 8.38(\mathrm{~s}, 1 \mathrm{H}), 8.22(\mathrm{t}, J=2.4 \mathrm{~Hz}$, $1 \mathrm{H}), 7.96-7.92(\mathrm{~m}, 1 \mathrm{H}), 7.82-7.79(\mathrm{~m}, 1 \mathrm{H}), 7.67-7.53(\mathrm{~m}$, $3 \mathrm{H}), 7.41-7.37(\mathrm{~m}, 1 \mathrm{H}), 3.58(\mathrm{q}, J=4.1 \mathrm{~Hz}, 4 \mathrm{H}), 3.29(\mathrm{~d}, J=$ $3.2 \mathrm{~Hz}, 2 \mathrm{H}), 2.50(\mathrm{~d}, J=4.4 \mathrm{~Hz}, 4 \mathrm{H}) ;{ }^{13} \mathrm{C} \mathrm{NMR}(101 \mathrm{MHz}$, DMSO- $\left.d_{6}\right) \delta 168.98,163.56,157.90,149.11,139.55,135.53$, $135.14,134.85,131.73,131.23,130.04,129.48,128.52,121.94$, 120.41, 118.49, 108.85, 66.58, 60.80, 53.39; HRMS $(\mathrm{m} / \mathrm{z})$ : calcd. For $\mathrm{C}_{22} \mathrm{H}_{21} \mathrm{Cl}_{2} \mathrm{~N}_{4} \mathrm{O}_{3} \mathrm{~S}$ (neutral $\mathrm{M}+\mathrm{H}$ ) 491.07114, found 491.07212 .

2,4-dichloro-N-(3-(2-(2-morpholinoacetamido)thiazol-4yl)phenyl)benzamide 5c: White solid; yield, 70.1\%; m.p.: $199.7^{\circ} \mathrm{C}-200.2^{\circ} \mathrm{C} ;{ }^{1} \mathrm{H}$ NMR (400 MHz, DMSO- $\left.d_{6}\right) \delta 12.16(\mathrm{~s}$, $1 \mathrm{H}), 10.66(\mathrm{~s}, 1 \mathrm{H}), 8.43(\mathrm{~s}, 1 \mathrm{H}), 7.81(\mathrm{~d}, J=1.9 \mathrm{~Hz}, 1 \mathrm{H})$, $7.61-7.58(\mathrm{~m}, 2 \mathrm{H}), 7.60(\mathrm{~d}, J=8.5 \mathrm{~Hz}, 2 \mathrm{H}), 7.55-7.52(\mathrm{~m}, 1 \mathrm{H})$, $7.43(\mathrm{t}, J=7.9 \mathrm{~Hz}, 1 \mathrm{H}), 3.63(\mathrm{t}, J=4.6 \mathrm{~Hz}, 4 \mathrm{H}), 3.34(\mathrm{~s}, 2 \mathrm{H})$, $2.55(\mathrm{t}, J=4.3 \mathrm{~Hz}, 4 \mathrm{H}) ;{ }^{13} \mathrm{C}$ NMR $\left(101 \mathrm{MHz}, \mathrm{DMSO}-d_{6}\right) \delta$ $168.98,164.49,157.92,149.06,139.53,136.15,135.28,131.65$, 130.77, 129.64, 129.60, 127.92, 121.90, 119.60, 117.59, 108.94, $66.57,60.77,53.37$; HRMS $(m / z)$ : calcd. For $\mathrm{C}_{22} \mathrm{H}_{21} \mathrm{Cl}_{2} \mathrm{~N}_{4} \mathrm{O}_{3} \mathrm{~S}$ (neutral $\mathrm{M}+\mathrm{H}$ ) 491.07114, found 491.07446. 
3-chloro-N-(3-(2-(2-morpholinoacetamido)thiazol-4$y$ l)phenyl)benzamide 5d: White solid; yield, 74.5\%; m.p.: $164.3^{\circ} \mathrm{C}-166.9^{\circ} \mathrm{C} ;{ }^{1} \mathrm{H}$ NMR $\left(400 \mathrm{MHz}, \mathrm{DMSO}-d_{6}\right) \delta 12.07$ (s, $1 \mathrm{H}), 10.42(\mathrm{~d}, J=3.4 \mathrm{~Hz}, 1 \mathrm{H}), 8.39(\mathrm{~s}, 1 \mathrm{H}), 8.01(\mathrm{~s}, 1 \mathrm{H})$, 7.95-7.88 (m, 1H), 7.69-7.49 (m, 5H), 7.41-7.36 (m, 1H), $3.58(\mathrm{q}, J=4.1 \mathrm{~Hz}, 4 \mathrm{H}), 3.29(\mathrm{~s}, 2 \mathrm{H}), 2.50(\mathrm{~d}, J=4.6 \mathrm{~Hz}$, $4 \mathrm{H}) ;{ }^{13} \mathrm{C}$ NMR $\left(101 \mathrm{MHz}, \mathrm{DMSO}-d_{6}\right) \delta 168.98,164.47$, $157.89,149.15,139.69,137.23,135.12,133.65,131.89$, $130.89,129.45,127.84,126.95,121.84,120.41,118.47$, $108.82,66.57,60.79,53.39$; HRMS $(\mathrm{m} / z)$ : calcd. For $\mathrm{C}_{22} \mathrm{H}_{22} \mathrm{ClN}_{4} \mathrm{O}_{3} \mathrm{~S}$ (neutral $\mathrm{M}+\mathrm{H}$ ) 457.11011, found 457.12488 .

3-bromo-N-(3-(2-(2-morpholinoacetamido)thiazol-4$y l$ )phenyl)benzamide $5 \boldsymbol{e}$ : White solid; yield, 74.6\%; m.p.: $223.3^{\circ} \mathrm{C}-224.4^{\circ} \mathrm{C} ;{ }^{1} \mathrm{H}$ NMR $\left(400 \mathrm{MHz}, \mathrm{DMSO}-d_{6}\right) \delta 12.13$ (s, 1H), $10.47(\mathrm{~s}, 1 \mathrm{H}), 8.45(\mathrm{~s}, 1 \mathrm{H}), 8.07(\mathrm{~s}, 1 \mathrm{H}), 8.01-7.89$ $(\mathrm{m}, 2 \mathrm{H}), 7.68(\mathrm{~d}, J=9.5 \mathrm{~Hz}, 3 \mathrm{H}), 7.61(\mathrm{~s}, 1 \mathrm{H}), 7.44(\mathrm{~d}, J=$ $6.9 \mathrm{~Hz}, 1 \mathrm{H}), 3.63(\mathrm{~s}, 4 \mathrm{H}), 3.34(\mathrm{~d}, J=4.1 \mathrm{~Hz}, 2 \mathrm{H}), 2.56(\mathrm{~s}$, $4 \mathrm{H}) ;{ }^{13} \mathrm{C}$ NMR $\left(101 \mathrm{MHz}, \mathrm{DMSO}-d_{6}\right) \delta 168.98,164.47$, $157.89,149.15,139.68,137.22,135.11,133.64,132.99$, $131.89,131.05,130.89,129.44,129.24,128.33,127.84$, 126.95, 121.83, 120.41, 118.47, 108.81, 66.57, 60.79, 53.39; HRMS $(m / z)$ : calcd. For $\mathrm{C}_{22} \mathrm{H}_{22} \mathrm{BrN}_{4} \mathrm{O}_{3} \mathrm{~S}$ (neutral $\mathrm{M}+\mathrm{H}$, $\mathrm{M}+2+\mathrm{H}) 501.05960$, found 501.06635, 503.06461 .

4-bromo-N-(3-(2-(2-morpholinoacetamido)thiazol-4$y l$ )phenyl)benzamide $5 f$ : White solid; yield, 74.6\%; m.p.: $223.3^{\circ} \mathrm{C}-224.4^{\circ} \mathrm{C}$; ${ }^{1} \mathrm{H}$ NMR $\left(400 \mathrm{MHz}, \mathrm{DMSO}-d_{6}\right) \delta 12.13$ (s, 1H), 10.47 (s, 1H), 8.45 (s, 1H), 8.07 (s, 1H), 8.01-7.89 $(\mathrm{m}, 2 \mathrm{H}), 7.68(\mathrm{~d}, J=9.5 \mathrm{~Hz}, 3 \mathrm{H}), 7.61(\mathrm{~s}, 1 \mathrm{H}), 7.44(\mathrm{~d}, J=$ $6.9 \mathrm{~Hz}, 1 \mathrm{H}), 3.63(\mathrm{~s}, 4 \mathrm{H}), 3.34(\mathrm{~d}, J=4.1 \mathrm{~Hz}, 2 \mathrm{H}), 2.56(\mathrm{~s}$, $4 \mathrm{H}) ;{ }^{13} \mathrm{C}$ NMR $\left(101 \mathrm{MHz}, \mathrm{DMSO}-d_{6}\right) \delta 168.98,164.47$, $157.89,149.15,139.68,137.22,135.11,133.64,131.89$, $130.89,129.44,127.84,126.95,121.83,120.41,118.47$, $108.81,66.57,60.79,53.39$; HRMS $(\mathrm{m} / z)$ : calcd. For $\mathrm{C}_{22} \mathrm{H}_{22} \mathrm{BrN}_{4} \mathrm{O}_{3} \mathrm{~S}$ (neutral $\mathrm{M}+\mathrm{H}, \mathrm{M}+2+\mathrm{H}$ ) 501.05960, found $501.06635,503.06462$.

4-fluoro-N-(3-(2-(2-morpholinoacetamido)thiazol-4$y l$ )phenyl)benzamide $5 \mathrm{~g}$ : White solid; yield, 75.4\%; m.p.: $175.5^{\circ} \mathrm{C}-177.1^{\circ} \mathrm{C} ;{ }^{1} \mathrm{H}$ NMR $\left(400 \mathrm{MHz}, \mathrm{DMSO}-d_{6}\right) \delta 12.07$ $(\mathrm{s}, 1 \mathrm{H}), 10.33(\mathrm{~d}, J=3.4 \mathrm{~Hz}, 1 \mathrm{H}), 8.39(\mathrm{~d}, J=3.2 \mathrm{~Hz}, 1 \mathrm{H})$, 8.06-8.01 (m, 2H), $7.61(\mathrm{~d}, J=8.0 \mathrm{~Hz}, 2 \mathrm{H}), 7.55(\mathrm{~d}, J=$ $2.7 \mathrm{~Hz}, 1 \mathrm{H}), 7.40-7.33(\mathrm{~m}, 3 \mathrm{H}), 3.58(\mathrm{q}, J=4.1 \mathrm{~Hz}, 4 \mathrm{H})$, $3.29(\mathrm{~d}, J=3.3 \mathrm{~Hz}, 2 \mathrm{H}), 2.50(\mathrm{~d}, J=4.8 \mathrm{~Hz}, 4 \mathrm{H}) ;{ }^{13} \mathrm{C} \mathrm{NMR}$ $\left(101 \mathrm{MHz}, \mathrm{DMSO}-d_{6}\right) \delta 168.98,165.76,164.84,163.28$, $157.88,149.20,139.86,135.09,131.70,131.67,130.89$, $130.80,129.41,121.66,120.40,118.47,115.91,115.69$, $108.77,66.58,60.80,53.39$; HRMS $(\mathrm{m} / z)$ : calcd. For $\mathrm{C}_{22} \mathrm{H}_{22} \mathrm{FN}_{4} \mathrm{O}_{3} \mathrm{~S}$ (neutral $\mathrm{M}+\mathrm{H}$ ) 441.13966, found 441.14145 .

3-fluoro-N-(3-(2-(2-morpholinoacetamido)thiazol-4yl)phenyl)benzamide $5 \boldsymbol{h}$ : White solid; yield, 74.8\%; m.p.: $149.5^{\circ} \mathrm{C}-150.6^{\circ} \mathrm{C} ;{ }^{1} \mathrm{H}$ NMR $\left(400 \mathrm{MHz}, \mathrm{DMSO}-d_{6}\right) \delta 12.07$ $(\mathrm{s}, 1 \mathrm{H}), 10.38(\mathrm{~d}, J=3.4 \mathrm{~Hz}, 1 \mathrm{H}), 8.40(\mathrm{~d}, J=3.0 \mathrm{~Hz}, 1 \mathrm{H})$, $7.82-7.76(\mathrm{~m}, 2 \mathrm{H}), 7.66-7.52(\mathrm{~m}, 4 \mathrm{H}), 7.48-7.34(\mathrm{~m}, 2 \mathrm{H})$, $4.02(\mathrm{~s}, 0 \mathrm{H}), 3.58(\mathrm{~d}, J=4.5 \mathrm{~Hz}, 4 \mathrm{H}), 3.29(\mathrm{~d}, J=3.5 \mathrm{~Hz}$, $2 \mathrm{H}), 2.58-2.42(\mathrm{~m}, 4 \mathrm{H}) ;{ }^{13} \mathrm{C}$ NMR $\left(101 \mathrm{MHz}, \mathrm{DMSO}-d_{6}\right)$ $\delta 168.98,164.54,163.57,161.14,157.89,149.16,139.68$, $137.58,137.51,135.11,131.10,131.02,129.44,124.35$, $124.32,121.82,120.43,119.08,118.87,118.50,115.05$,
114.82, 108.81, 66.57, 60.79, 53.39; HRMS $(\mathrm{m} / z)$ : calcd. For $\mathrm{C}_{22} \mathrm{H}_{22} \mathrm{FN}_{4} \mathrm{O}_{3} \mathrm{~S}$ (neutral $\mathrm{M}+\mathrm{H}$ ) 441.13966, found 441.15094.

N-(3-(2-(2-morpholinoacetamido)thiazol-4-yl)phenyl)-3(trifluoromethyl)benzamide 5i: White solid; yield, 74.8\%; m. p.: $103.4^{\circ} \mathrm{C}-105.1^{\circ} \mathrm{C} ;{ }^{1} \mathrm{H}$ NMR (400 MHz, DMSO- $\left.d_{6}\right) \delta 12.07$ (s, $1 \mathrm{H}), 10.55(\mathrm{~d}, J=3.4 \mathrm{~Hz}, 1 \mathrm{H}), 8.38(\mathrm{~s}, 1 \mathrm{H}), 8.30(\mathrm{~s}, 1 \mathrm{H})$, $8.26(\mathrm{~d}, J=8.0 \mathrm{~Hz}, 1 \mathrm{H}), 7.95(\mathrm{~d}, J=7.9 \mathrm{~Hz}, 1 \mathrm{H}), 7.82-7.72$ $(\mathrm{m}, 1 \mathrm{H}), 7.64(\mathrm{~d}, J=7.9 \mathrm{~Hz}, 2 \mathrm{H}), 7.57(\mathrm{~d}, J=3.4 \mathrm{~Hz}, 1 \mathrm{H})$, $7.42-7.38(\mathrm{~m}, 1 \mathrm{H}), 3.57(\mathrm{t}, J=4.3 \mathrm{~Hz}, 4 \mathrm{H}), 3.29$ (s, 2H), 2.50 $(\mathrm{d}, J=5.1 \mathrm{~Hz}, 4 \mathrm{H}) ;{ }^{13} \mathrm{C} \mathrm{NMR}\left(101 \mathrm{MHz}, \mathrm{DMSO}-d_{6}\right) \delta 168.98$, $164.43,157.90,149.11,139.61,136.10,135.14,133.65,132.34$, $130.50,130.22,129.75,129.48,128.65,124.68,124.64,121.92$, 120.50, 118.59, 108.84, 66.57, 60.80, 53.39; HRMS $(\mathrm{m} / z)$ : calcd. For $\mathrm{C}_{23} \mathrm{H}_{22} \mathrm{~F}_{3} \mathrm{~N}_{4} \mathrm{O}_{3} \mathrm{~S}$ (neutral $\mathrm{M}+\mathrm{H}$ ) 491.13647, found 491.15257.

N-(3-(2-(2-morpholinoacetamido)thiazol-4-yl)phenyl)-4(trifluoromethyl)benzamide 5j: White solid; yield, 76.7\%; m. p.: $146.9^{\circ} \mathrm{C}-148.8^{\circ} \mathrm{C} ;{ }^{1} \mathrm{H}$ NMR $\left(400 \mathrm{MHz}, \mathrm{DMSO}-d_{6}\right) \delta 12.07$ (s, 1H), $10.61(\mathrm{~s}, 1 \mathrm{H}), 8.41(\mathrm{~s}, 1 \mathrm{H}), 8.16(\mathrm{~d}, J=7.7 \mathrm{~Hz}, 2 \mathrm{H})$, $7.90(\mathrm{~d}, J=8.0 \mathrm{~Hz}, 2 \mathrm{H}), 7.63(\mathrm{~d}, J=8.1 \mathrm{~Hz}, 2 \mathrm{H}), 7.56(\mathrm{~d}, J=$ $3.1 \mathrm{~Hz}, 1 \mathrm{H}), 7.39$ (t, $J=7.9 \mathrm{~Hz}, 1 \mathrm{H}), 3.58(\mathrm{~d}, J=4.6 \mathrm{~Hz}, 4 \mathrm{H})$, $3.29(\mathrm{~d}, J=3.2 \mathrm{~Hz}, 2 \mathrm{H}), 2.50(\mathrm{~d}, J=4.8 \mathrm{~Hz}, 4 \mathrm{H}) ;{ }^{13} \mathrm{C} \mathrm{NMR}$ $\left(101 \mathrm{MHz}, \mathrm{DMSO}-d_{6}\right) \delta 169.05,164.82,158.03,149.11$, 139.64, 139.08, 135.16, 131.95, 131.64, 129.94, 129.46, 129.07, $125.90,125.87,125.83,125.79,125.71,124.52,123.00,121.92$, $120.46,118.52,108.80,66.58,60.84,53.39$; HRMS $(\mathrm{m} / z)$ : calcd. For $\mathrm{C}_{23} \mathrm{H}_{22} \mathrm{~F}_{3} \mathrm{~N}_{4} \mathrm{O}_{3} \mathrm{~S}$ (neutral $\mathrm{M}+\mathrm{H}$ ) 491.13647, found 491.14793.

N-(3-(2-(2-morpholinoacetamido)thiazol-4-yl)phenyl)furan2-carboxamide $5 \boldsymbol{k}$ : White solid; yield, $88.2 \%$; m.p.: $189.5^{\circ} \mathrm{C}-$ $190.8^{\circ} \mathrm{C} ;{ }^{1} \mathrm{H}$ NMR (400 MHz, DMSO- $\left.d_{6}\right) \delta 12.12(\mathrm{~s}, 1 \mathrm{H}), 10.29$ $(\mathrm{s}, 1 \mathrm{H}), 8.38(\mathrm{t}, J=1.9 \mathrm{~Hz}, 1 \mathrm{H}), 7.97(\mathrm{~d}, J=1.6 \mathrm{~Hz}, 1 \mathrm{H}), 7.66(\mathrm{t}, J$ $=1.9 \mathrm{~Hz}, 1 \mathrm{H}), 7.64(\mathrm{t}, J=1.8 \mathrm{~Hz}, 1 \mathrm{H}), 7.59(\mathrm{~s}, 1 \mathrm{H}), 7.42(\mathrm{~d}, J=$ $7.9 \mathrm{~Hz}, 1 \mathrm{H}), 7.38(\mathrm{~d}, J=3.3 \mathrm{~Hz}, 1 \mathrm{H}), 6.74-6.73(\mathrm{~m}, 1 \mathrm{H}), 3.62(\mathrm{t}, J$ $=4.6 \mathrm{~Hz}, 4 \mathrm{H}), 3.33(\mathrm{~s}, 2 \mathrm{H}), 2.54(\mathrm{t}, J=4.6 \mathrm{~Hz}, 4 \mathrm{H}) ;{ }^{13} \mathrm{C} \mathrm{NMR}$ $\left(101 \mathrm{MHz}, \mathrm{DMSO}-d_{6}\right) \delta 164.37,153.28,152.05,144.56,143.27$, $141.65,134.73,130.50,124.83,117.05,115.77,113.84,110.61$, 108.01, 104.19, 61.98, 56.20, 48.79; HRMS (m/z): calcd. For $\mathrm{C}_{20} \mathrm{H}_{21} \mathrm{~N}_{4} \mathrm{O}_{4} \mathrm{~S}$ (neutral $\mathrm{M}+\mathrm{H}$ ) 413.12835, found 413.13295 .

2-methoxy-N-(3-(2-(2-morpholinoacetamido)thiazol4-yl)phenyl)acetamide 5l: Yellow solid; yield, 85.2\%; m. p.: $137.0^{\circ} \mathrm{C}-139.5^{\circ} \mathrm{C} ;{ }^{1} \mathrm{H}$ NMR $\left(400 \mathrm{MHz}, \mathrm{DMSO}-d_{6}\right) \delta$ $12.22(\mathrm{~s}, 1 \mathrm{H}), 9.79(\mathrm{~s}, 1 \mathrm{H}), 8.27(\mathrm{~s}, 1 \mathrm{H}), 7.56(\mathrm{~d}, J=7.7 \mathrm{~Hz}$, $1 \mathrm{H}), 7.52(\mathrm{~d}, J=2.7 \mathrm{~Hz}, 1 \mathrm{H}), 7.49(\mathrm{~d}, J=8.0 \mathrm{~Hz}, 1 \mathrm{H})$, $7.35-7.30(\mathrm{~m}, 1 \mathrm{H}), 4.14(\mathrm{~d}, J=2.9 \mathrm{~Hz}, 2 \mathrm{H}), 3.98(\mathrm{~d}, J=$ $2.9 \mathrm{~Hz}, 2 \mathrm{H}), 3.35(\mathrm{~d}, J=1.9 \mathrm{~Hz}, 11 \mathrm{H}) ;{ }^{13} \mathrm{C} \mathrm{NMR}$ $\left(101 \mathrm{MHz}, \mathrm{DMSO}-d_{6}\right) \delta 169.04,168.55,157.75,149.19$, $139.21,135.08,129.42,121.48,119.78,117.81,108.80$, 72.09, 70.86, 59.18, 59.09; HRMS $(\mathrm{m} / z)$ : calcd. For $\mathrm{C}_{18} \mathrm{H}_{23} \mathrm{~N}_{4} \mathrm{O}_{4} \mathrm{~S}$ (neutral $\mathrm{M}+\mathrm{H}$ ) 391.14400, found 391.14766.

N-(3-(2-(2-morpholinoacetamido)thiazol-4-yl)phenyl) cyclohexanecarboxamide $5 \mathrm{~m}$ : White solid; yield, $69.1 \%$; m.p.: $165.5^{\circ} \mathrm{C}-166.8^{\circ} \mathrm{C} ;{ }^{1} \mathrm{H}$ NMR $\left(400 \mathrm{MHz}, \mathrm{DMSO}-d_{6}\right)$ $\delta 12.13(\mathrm{~s}, 1 \mathrm{H}), 9.91(\mathrm{~s}, 1 \mathrm{H}), 8.31(\mathrm{~d}, J=1.8 \mathrm{~Hz}, 1 \mathrm{H})$, 7.55 (s, 1H), 7.44-7.41 (m, 1H), $7.33(\mathrm{t}, J=7.9 \mathrm{~Hz}, 1 \mathrm{H}), 3.62$ $(\mathrm{t}, J=4.6 \mathrm{~Hz}, 4 \mathrm{H}), 3.33(\mathrm{~s}, 2 \mathrm{H}), 2.54(\mathrm{~d}, J=4.5 \mathrm{~Hz}, 3 \mathrm{H})$, 2.39-2.31 (m, 1H), 1.87-1.73 (m, 5H), $1.67(\mathrm{~d}, J=11.5 \mathrm{~Hz}$, 
$1 \mathrm{H}), \quad 1.50-1.13(\mathrm{~m}, 6 \mathrm{H}) ;{ }^{13} \mathrm{C}$ NMR $\left(101 \mathrm{MHz}, \mathrm{DMSO}-d_{6}\right)$ $\delta 170.16,164.31,153.20,144.69,135.67,130.45,124.76$, $121.88,116.20,114.88,114.42,112.61,104.01,61.96,56.18$, 48.78, 40.64, 24.98, 21.24, 21.07; HRMS (m/z): calcd. For $\mathrm{C}_{22} \mathrm{H}_{29} \mathrm{~N}_{4} \mathrm{O}_{3} \mathrm{~S}$ (neutral $\mathrm{M}+\mathrm{H}$ ) 429.19604, found 429.20358.

$\mathrm{N}$-(4-(3-acetamidophenyl)thiazol-2-yl)-2-morpholinoacetamide 5n: White solid; yield, 95.1\%; m.p.: $206.7^{\circ} \mathrm{C}-208.0^{\circ} \mathrm{C} ;{ }^{1} \mathrm{H}$ NMR $\left(400 \mathrm{MHz}, \mathrm{DMSO}-d_{6}\right) \delta 12.06(\mathrm{~s}, 1 \mathrm{H}), 9.99(\mathrm{~s}, 1 \mathrm{H}), 8.18(\mathrm{t}$, $J=2.0 \mathrm{~Hz}, 1 \mathrm{H}), 7.55-7.43(\mathrm{~m}, 2 \mathrm{H}), 7.40(\mathrm{~d}, J=8.2 \mathrm{~Hz}, 1 \mathrm{H})$, $7.32-7.27(\mathrm{~m}, 1 \mathrm{H}), 3.57(\mathrm{p}, J=2.2 \mathrm{~Hz}, 4 \mathrm{H}), 3.28(\mathrm{t}, J=$ $1.8 \mathrm{~Hz}, 2 \mathrm{H}), 2.50-2.48(\mathrm{~m}, 4 \mathrm{H}), 2.02(\mathrm{t}, J=1.7 \mathrm{~Hz}, 3 \mathrm{H})$; ${ }^{13} \mathrm{C}$ NMR $\left(101 \mathrm{MHz}, \mathrm{DMSO}-d_{6}\right) \delta 168.95,168.77,157.83$, $149.23,140.11,135.11,129.44,120.94,118.92,116.97$, 108.69, 66.57, 60.77, 53.38, 24.49; HRMS (m/z): calcd. For $\mathrm{C}_{17} \mathrm{H}_{21} \mathrm{~N}_{4} \mathrm{O}_{3} \mathrm{~S}$ (neutral $\mathrm{M}+\mathrm{H}$ ) 361.13344, found 361.13903.

2-chloro-N-(3-(2-(2-morpholinoacetamido)thiazol-4yl)phenyl)acetamide 5o: White solid; yield, 88.1\%; m.p.: $209.1^{\circ} \mathrm{C}-211.0^{\circ} \mathrm{C} ;{ }^{1} \mathrm{H}$ NMR (400 MHz, DMSO- $\left.d_{6}\right) \delta 12.11$ $(\mathrm{s}, 1 \mathrm{H}), 10.39(\mathrm{~s}, 1 \mathrm{H}), 8.22(\mathrm{~d}, J=1.8 \mathrm{~Hz}, 1 \mathrm{H}), 7.60-7.55$ $(\mathrm{m}, 1 \mathrm{H}), 7.55(\mathrm{~s}, 1 \mathrm{H}), 7.44-7.29(\mathrm{~m}, 2 \mathrm{H}), 4.24(\mathrm{~s}, 2 \mathrm{H})$, $3.58(\mathrm{t}, J=4.5 \mathrm{~Hz}, 4 \mathrm{H}), 3.33(\mathrm{~s}, 2 \mathrm{H}), 2.54-2.49(\mathrm{~m}, 4 \mathrm{H})$; ${ }^{13} \mathrm{C}$ NMR $\left(101 \mathrm{MHz}, \mathrm{DMSO}-d_{6}\right) \delta 165.12,157.87,148.98$, $139.27,135.25,129.66,126.66,121.72,119.30,117.39$, 108.96, 66.48, 60.68, 53.35, 44.05; HRMS $(\mathrm{m} / z)$ : calcd. For $\mathrm{C}_{17} \mathrm{H}_{20} \mathrm{ClN}_{4} \mathrm{O}_{3} \mathrm{~S}$ (neutral $\mathrm{M}+\mathrm{H}$ ) 395.09446, found 395.09562 .

3.2. Primary Anticancer Assay. The cells were seeded in 96well microplates at a density of $5 \times 10^{3}$ cells per well and incubated with $5 \% \mathrm{CO}_{2}$ at $37^{\circ} \mathrm{C}$ overnight. On the next day, the target compounds were added into the culture medium. The final concentration of DMSO in the medium was less than $0.5 \%$. Triplicates of each concentration were used. After the cells were treated with compounds for $24 \mathrm{~h}$, the supernatant was removed, and $5 \mathrm{mg} / \mathrm{mL}$ of a fresh prepared solution of MTT was added to each well and incubated with the cells at $37^{\circ} \mathrm{C}$ for another $4 \mathrm{~h}$. The medium was removed, and $100 \mu \mathrm{L}$ of DMSO was added to each well to dissolve formazan. The absorbances at $490 \mathrm{~nm}$ (for absorbance of MTT formazan) and $630 \mathrm{~nm}$ (for the reference wavelength) were measured by the microplate reader. Cell growth inhibition rates formula is $(\mathrm{AC}-\mathrm{AT}) / \mathrm{AC} \times 100 \%(\mathrm{AC}$, absorbance value of the blank control group; AT, absorbance value of the experimental group). The $\mathrm{IC}_{50}$ was calculated using GraphPad Prism version 6.00 software from the nonlinear curve.

3.3. Kinase Assay. The c-Met activity was performed by enzyme-linked immunosorbent assay (ELISA), and $20 \mu \mathrm{g} / \mathrm{mL}$ poly (Glu, Tyr) 4:1 (Sigma) was precoated in 96well plates. Then, $50 \mu \mathrm{L}$ of $10 \mu \mathrm{mol} / \mathrm{L}$ ATP solution diluted in kinase reaction buffer $(50 \mathrm{mmol} / \mathrm{L}$ HEPES, pH 7.4, $50 \mathrm{mmol} / \mathrm{L} \mathrm{MgCl}_{2}, 0.5 \mathrm{mmol} / \mathrm{L} \mathrm{MnCl}_{2}, 0.2 \mathrm{mmol} / \mathrm{L} \mathrm{Na}_{3} \mathrm{VO}_{4}$, and $1 \mathrm{mmol} / \mathrm{L}$ DTT) was added to each well. Various concentrations of compound $\mathbf{5 b}$ diluted in $1 \%$ DMSO $(\mathrm{v} / \mathrm{v})$ were added to each reaction well. Blank DMSO (1\% v/v) was used as the negative control. The kinase reaction was initiated after the addition of purified tyrosine kinase proteins. After incubation for $60 \mathrm{~min}$ at $37^{\circ} \mathrm{C}$, the plate was washed three times with phosphate buffered saline (PBS) containing $0.1 \%$ Tween 20 (T-PBS). Then antiphosphotyrosine (PY99) antibody (1:500 diluted in $5 \mathrm{mg} / \mathrm{mL}$ BSA TPBS) was then added. After $30 \mathrm{~min}$ incubation at $37^{\circ} \mathrm{C}$, the plate was washed three times. Horseradish peroxidase-conjugated goat antimouse IgG (1:2000 diluted in $5 \mathrm{mg} / \mathrm{mL}$ BSA T-PBS) was added. The plate was then incubated at $37^{\circ} \mathrm{C}$ for $30 \mathrm{~min}$ and washed three times. Finally, a solution containing $0.03 \%$ $\mathrm{H}_{2} \mathrm{O}_{2}$ and $2 \mathrm{mg} / \mathrm{mL} o$-phenylenediamine in $0.1 \mathrm{~mol} / \mathrm{L}$ citrate buffer ( $\mathrm{pH}$ 5.5) was added. The reaction was terminated by the addition of $2 \mathrm{~mol} / \mathrm{L} \mathrm{H}_{2} \mathrm{SO}_{4}$, and the plate was read using a multiwell spectrophotometer ((VERSAmax ${ }^{\mathrm{TM}}$, Molecular Devices) at $490 \mathrm{~nm}$. The inhibition rate (\%) was calculated using the following equation: $(1-\mathrm{A} 490 /(\mathrm{A} 490$ control $)) \times$ $100 \% . \mathrm{IC}_{50}$ values were calculated from the inhibition curve.

3.4. Western Blot. Cells were harvested and washed twice with cold PBS, stimulated with HGF (40 ng/mL) for $15 \mathrm{~min}$, then resuspended and lysed in RIPA buffer $(150 \mathrm{mM} \mathrm{NaCl}$, $1 \%$ NP-40, $1 \%$ SDS, $1 \mathrm{mM}$ PMSF, $10 \mu \mathrm{g} / \mathrm{ml}$ leupeptin, $1 \mathrm{mM}$ aprotinin, $50 \mathrm{mM}$ Tris- $\mathrm{Cl}, \mathrm{pH} 7.4$ ) at $4^{\circ} \mathrm{C}$ for $30 \mathrm{~min}$. The protein concentration was determined by the BCA assay. Cell lysate was separated by $10 \%$ SDS-PAGE, and then transferred to PVDF membranes. The membranes were blocked with $5 \%$ nonfat milk and incubated with primary antibodies at $4^{\circ} \mathrm{C}$ overnight. Horseradish peroxidaseconjugated secondary antibodies were used against corresponding primary antibody at room temperature. Bound antibodies were revealed by the enhanced chemiluminescence (ECL) technique.

3.5. Molecular Docking. Molecular docking was performed using the CDOCKER protocol (the Discovery Studio 3.5 software package, Accelrys, Co. Ltd). The cocrystal structure of c-Met (PDB code 2WGJ) was downloaded from the RCSB Protein Data Bank (http://www.rcsb.org). Protein preparation was carried out using the Prepare Protein protocol, and all bound water was deleted from the protein. The ligand preparation was carried out using the Prepare Ligand protocol. The docking parameters were set as default. The lowest binding energy was taken as the best-docked conformation of the ligand for the protein.

\section{Conclusion}

A series of new substituted 2-amino-4-phenylthiazole derivatives were designed and synthesized according to the structural characteristics of crizotinib and screened for biological activity. Some of these novel compounds have mild to good anticancer activity. Among these compounds, compound $\mathbf{5 b}$ possessed outstanding growth inhibitory effects, especially for HT29 cells with an $\mathrm{IC}_{50}$ value of $2.01 \mu \mathrm{M}$. Further experimental results support that the target compounds may be potential inhibitors of c-Met kinase. 


\section{Data Availability}

The data used to support the findings of this study are included within the article. The ${ }^{1} \mathrm{H}$ NMR and ${ }^{13} \mathrm{C}$ NMR of synthesized compounds used to support the findings of this study are included within the supplementary information file.

\section{Conflicts of Interest}

The authors declare that they have no conflicts of interest.

\section{Acknowledgments}

This work was supported by the National Natural Science Foundation of China (No. 21601075), the Natural Science Foundation of Liaoning Province (No. 2015020249 and No. 20170540396), and General Research Projects of Liaoning Provincial Department of Education (No. JQL201715410).

\section{Supplementary Materials}

${ }^{1} \mathrm{H}$ NMR and ${ }^{13} \mathrm{C}$ NMR spectra for the prepared compounds are available in Supplementary Materials. (Supplementary Materials)

\section{References}

[1] M. Dobbelstein and U. Moll, "Targeting tumour-supportive cellular machineries in anticancer drug development," Nature reviews Drug discovery, vol. 13, no. 3, pp. 179-196, 2014.

[2] Z. Y. Liu, Y. M. Wang, Z. R. Li, J. D. Jiang, and D. W. Boykin, "Synthesis and anticancer activity of novel 3,4-diarylthiazol-2 (3H)-ones (imines)," Bioorganic \& medicinal chemistry letters, vol. 19, no. 19, pp. 5661-5664, 2009.

[3] Y.-S. E. Lee, S.-H. Chuang, L. Y. L. Huang et al., "Discovery of 4-aryl-N-arylcarbonyl-2-aminothiazoles as hec1/Nek2 inhibitors. Part I: optimization of in vitro potencies and pharmacokinetic properties," Journal of Medicinal Chemistry, vol. 57, no. 10, pp. 4098-4110, 2014.

[4] N. Siddiqui and W. Ahsan, "Synthesis, anticonvulsant and toxicity screening of thiazolyl-thiadiazole derivatives," $\mathrm{Me}$ dicinal Chemistry Research, vol. 20, no. 2, pp. 261-268, 2011.

[5] S. J. Kashyap, V. K. Garg, P. K. Sharma, N. Kumar, R. Dudhe, and J. K. Gupta, "Thiazoles: having diverse biological activities," Medicinal Chemistry Research, vol. 21, no. 8, pp. 2123-2132, 2012.

[6] G. Turan-Zitouni, P. Chevallet, F. S. Kiliç, and K. Erol, "Synthesis of some thiazolyl-pyrazoline derivatives and preliminary investigation of their hypotensive activity," European Journal of Medicinal Chemistry, vol. 35, no. 6, pp. 635-641, 2000.

[7] P. Arora, R. Narang, S. Bhatia, S. K. Nayak, S. K. Singh, and B. Narasimhan, "Synthesis, molecular docking and QSAR studies of 2, 4-disubstituted thiazoles as antimicrobial agents," Journal of Applied Pharmaceutical Science, vol. 5, no. 2, pp. 28-42, 2015.

[8] A. Gallardo-Godoy, J. Gever, K. L. Fife, B. M. Silber, S. B. Prusiner, and A. R. Renslo, "2-Aminothiazoles as therapeutic leads for prion diseases," Journal of Medicinal Chemistry, vol. 54, no. 4, pp. 1010-1021, 2011.

[9] A. A. Farghaly, A. A. Bekhit, and Y. P. Ji, "Design and synthesis of some oxadiazolyl, thiadiazolyl, thiazolidinyl, and thiazolyl derivatives of $1 \mathrm{H}$-pyrazole as anti-inflammatory antimicrobial agents," Archiv der Pharmazie, vol. 333, no. 2-3, pp. 53-57, 2000.

[10] D. J. Hadjipavlou-Litina and A. A. Geronikaki, "Thiazolyl and benzothiazolyl Schiff bases as novel possible lipoxygenase inhibitors and anti inflammatory agents. Synthesis and biological evaluation," Drug Design and Discovery, vol. 15, no. 3, pp. 199-206, 1998.

[11] K. W. Jeong, J. H. Lee, S. M. Park et al., "Synthesis and in-vitro evaluation of 2-amino-4-arylthiazole as inhibitor of 3D polymerase against foot-and-mouth disease (FMD)," European Journal of Medicinal Chemistry, vol. 102, no. 18, pp. 387-397, 2015.

[12] G. A. Hampannavar, R. Karpoormath, M. B. Palkar, M. S. Shaikh, and B. Chandrasekaran, "Dehydrozingerone inspired styryl hydrazine thiazole hybrids as promising class of antimycobacterial agents," ACS Medicinal Chemistry Letters, vol. 7, no. 7, pp. 686-691, 2016.

[13] M. S. Gill, A. Mital, S. S. Jhamb, V. S. Negi, R. P. Burman, and M. Jain, "Synthesis and biological evaluation of 2thiazolylimino-5-arylidene-4-thiazolidinone derivatives as potent antimycobacterial agents," Anti-Infective Agents, vol. 13, no. 2, pp. 105-113, 2015.

[14] C. H. Rios Martinez and A. A. Durant-Archibold, "Latest Research on synthetics compounds with antileishmanial activity," Mini-Reviews in Organic Chemistry, vol. 15, no. 4, pp. 330-342, 2018.

[15] S. L. Markant, L. A. Esparza, J. Sun et al., "Targeting sonic hedgehog-associated medulloblastoma through inhibition of Aurora and Polo-like kinases," Cancer Research and Treatment, vol. 73, no. 20, pp. 6310-6322, 2013.

[16] A. Jayanthan, Y. Ruan, T. H. Truong, and A. Narendran, "Aurora kinases as druggable targets in pediatric leukemia: heterogeneity in target modulation activities and cytotoxicity by diverse novel therapeutic agents," PLoS One, vol. 9, no. 7, Article ID e102741, 2014.

[17] S. K. Saha, J. D. Gordan, B. P. Kleinstiver et al., "Isocitrate dehydrogenase mutations confer dasatinib hypersensitivity and SRC dependence in intrahepatic cholangiocarcinoma," Cancer Discovery, vol. 6, no. 7, pp. 727-739, 2016.

[18] D. Zhang, J. Ai, Z. Liang et al., "Discovery of novel 2aminopyridine-3-carboxamides as c-Met kinase inhibitors," Bioorganic and Medicinal Chemistry, vol. 20, no. 17, pp. 5169-5180, 2012.

[19] R. Ingle, R. Marathe, D. Magar, H. M. Patel, and S. J. Surana, "Sulphonamido-quinoxalines: search for anticancer agent," European Journal of Medicinal Chemistry, vol. 65, no. 7, pp. 168-186, 2013.

[20] J. J. Cui, M. Tran-Dubé, H. Shen et al., "Structure based drug design of crizotinib (PF-02341066), a potent and selective dual inhibitor of mesenchymal-epithelial transition factor (cMET) kinase and anaplastic lymphoma kinase (ALK)," Journal of Medicinal Chemistry, vol. 54, no. 18, pp. 6342-6363, 2011.

[21] M. S. Coumar, C. Y. Chu, C. W. Lin et al., "Fast-forwarding hit to lead: aurora and epidermal growth factor receptor kinase inhibitor lead identification," Journal of Medicinal Chemistry, vol. 53, no. 13, pp. 4980-4988, 2010.

[22] C. A. Lipinski, "Lead- and drug-like compounds: the rule-offive revolution,” Drug Discovery Today: Technologies, vol. 1, no. 4, pp. 337-341, 2004. 

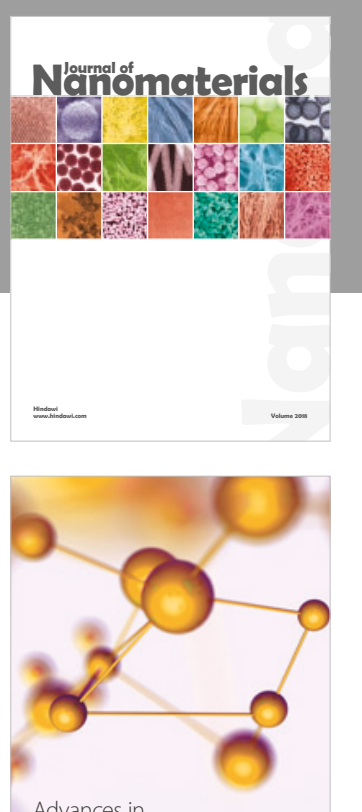

Physical Chemistry
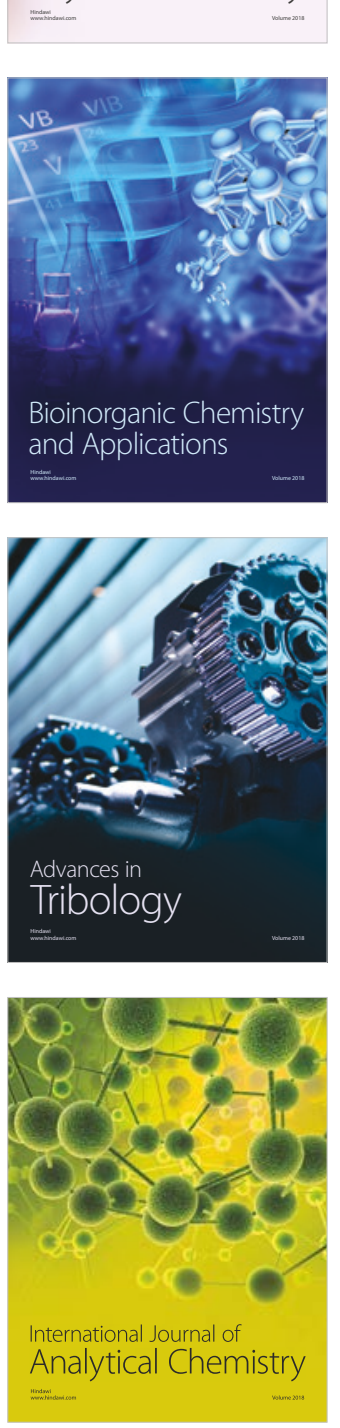

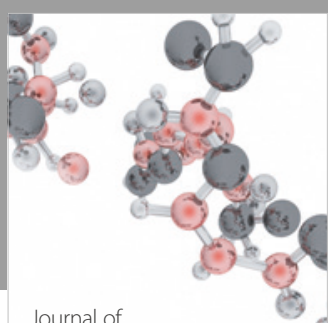

Analytical Methods

in Chemistry

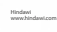

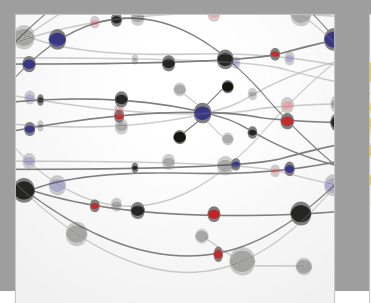

The Scientific World Journal

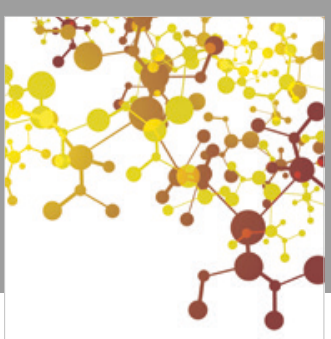

Journal of

Applied Chemistry
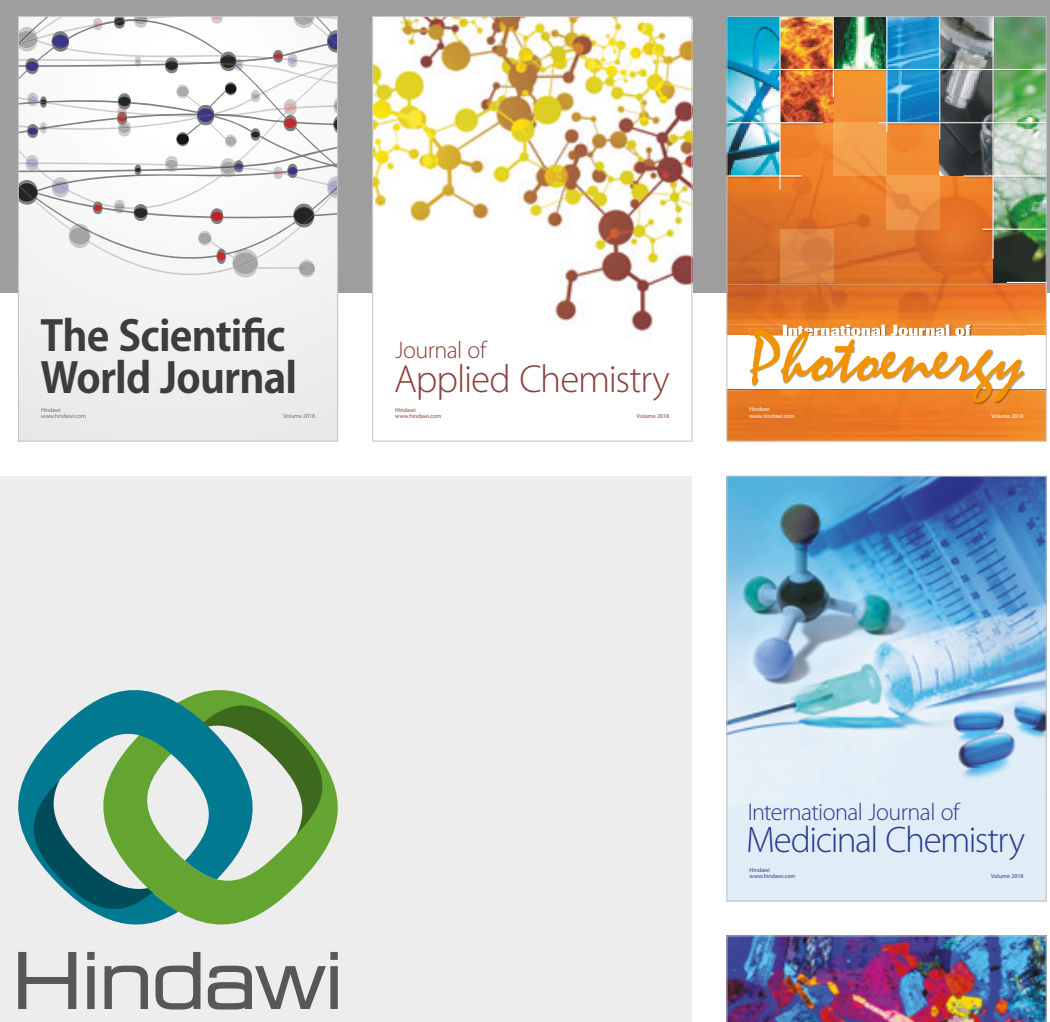

Submit your manuscripts at

www.hindawi.com
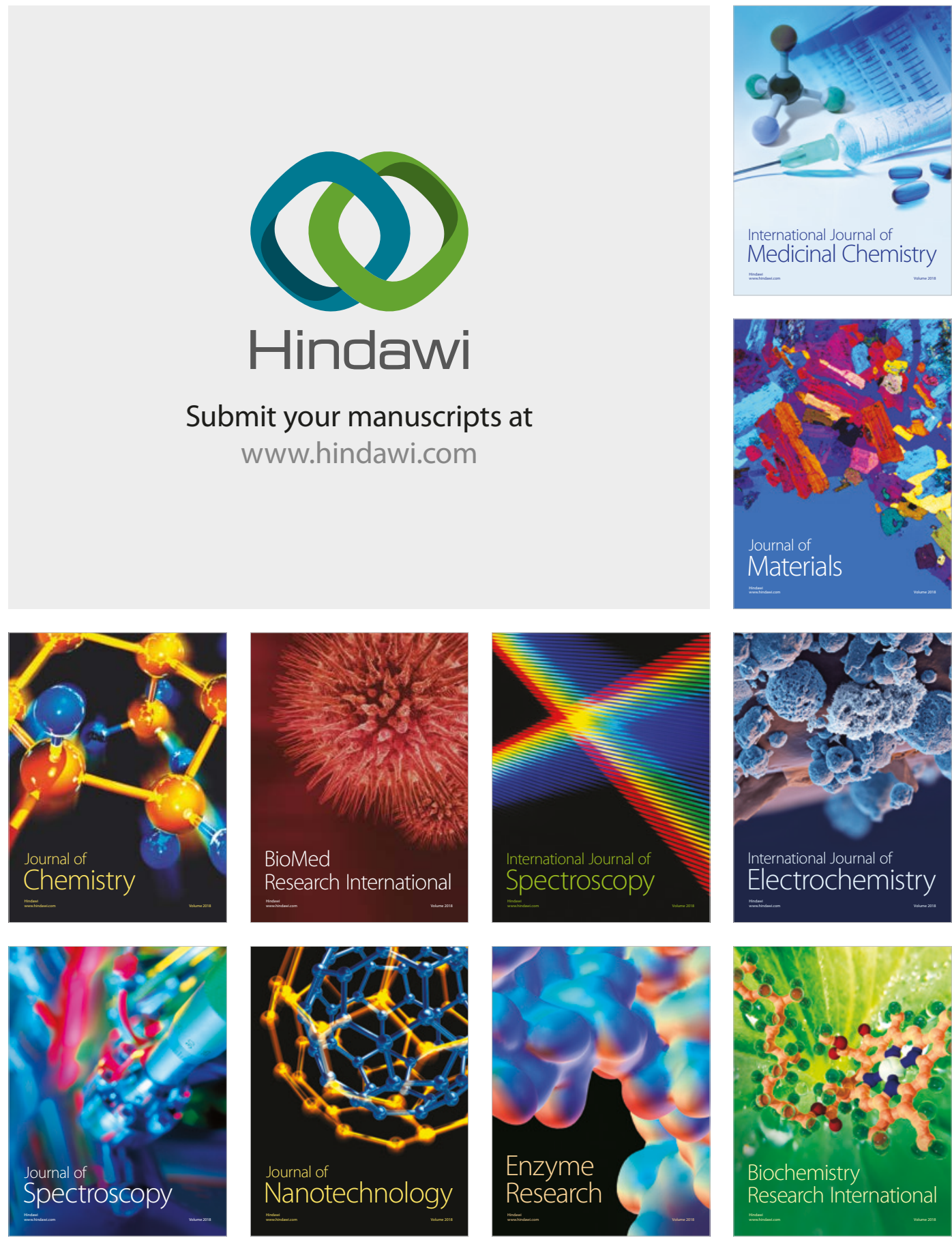
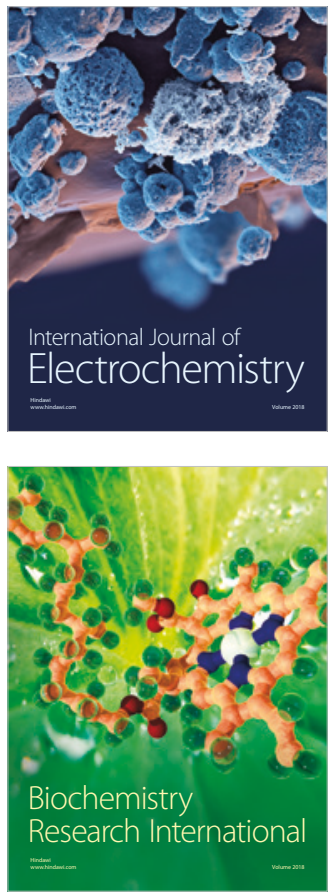